\title{
LA IRONÍA SOCRÁTICA COMO FORMA DE VIDA ${ }^{1}$ \\ Fernanda Rojas \\ Universidad Nacional Autónoma de México
}

\section{Resumen}

En Sobre el concepto de ironía, Kierkegaard comienza su análisis del concepto describiendo la ironía, a partir de Sócrates, como una absoluta e infinita negatividad ante la cual la vida del propio Sócrates termina sucumbiendo. Pero, hacia el final de su disertación, Kierkegaard afirma que la ironía es el comienzo de la vida digna de ser llamada humana. A primera vista, parece contradictorio que la ironía que cobró la vida de Sócrates pueda ser el principio de la vida humana, lo cual plantea la posibilidad de que esta última ironía no sea la que se introdujo con Sócrates. No obstante, pese a la contradicción señalada, hay buenas razones para sugerir que la ironía socrática es aquella que constituye el principio de la vida humana.

Palabras clave

Forma de vida, Kierkegaard, ironía, Sócrates, Romanticismo.

\section{Abstract}

In On the Concept of Irony, Kierkegaard begins his analysis of the concept by describing irony, starting with Socrates, as an absolute and infinite negativity, to which the life of Socrates ends up yielding. However, as his dissertation approaches conclusion, Kierkegaard claims that irony is the beginning of a life worthy of being called human. At first glance, it seems contradictory that the irony that took Socrates' life could be the beginning of human life, something that puts over the table the possibility that this irony is not that which was introduced with Socrates. Nonetheless, despite the marked contradiction, there are good reasons to believe that Socratic irony is that which the beginning of human life is.

Keywords

Way of Life, Kierkegaard, Irony, Socrates, Romanticism.

${ }^{1}$ Recibido: 14 de junio de 2015. Aceptado: 6 de julio de 2015. 
De manera explícita podemos encontrar en la disertación de Kierkegaard Sobre el concepto de ironía en constante referencia a Sócrates las siguientes tesis: aquella en la que se afirma que "Sócrates no solo utilizó la ironía, sino que además se consagró a la ironía hasta el punto de sucumbir a ella” (IV)²; y aquella otra en la que se afirma que "[a]sí como la filosofía comienza con la duda, la vida digna de ser llamada humana comienza con la ironía” (XV).

La primera de estas tesis es desarrollada en la caracterización que Kierkegaard hace de la ironía socrática con base en el análisis de los retratos de Sócrates hechos por Jenofonte, Platón y Aristófanes. En términos generales, Kierkegaard define la ironía como la oposición entre el fenómeno y la esencia, la realidad y la idea 4 . Esta oposición es introducida por Sócrates, cuando, en una época en la que la verdad establecida política y religiosamente, era aceptada por tradición o costumbre, mas no porque el individuo tuviera consciencia de ella. Sócrates niega todo lo establecido, haciendo que su realidad carezca de validez. La negatividad de la ironía que se introdujo con Sócrates consiste en que este rehúsa o sobrepasa todo fundamento de su realidad: rehúsa inmiscuirse en asuntos políticos ${ }^{5}$ y a tener relaciones interpersonales. No era amante ni maestro ${ }^{6}$, iba en contra de la religión del Estado ${ }^{7}$, buscaba liberarse de las determinaciones de la vida ${ }^{8}$, etc. Al negarlo todo, Sócrates llega a un estado de abstracción, de vacío, de nada, en el que se hace posible un cambio de mirada: no se mira hacia la verdad establecida objetivamente, sino que se inicia una búsqueda de la verdad a partir de la propia subjetividad. En este punto, Sócrates logra divisar a lo lejos la Idea. Esta se le presenta, pero solo como posibilidad'. Una vez planteada la posibilidad, serán sus sucesores los que propiamente alcanzarán la Idea, tal como se puede ver por el número de escuelas socráticas. Que Sócrates no alcanza la idea, sino que se suspende entre la realidad que negó

2 Søren Kierkegaard, Sobre el concepto de ironía, trad. de Darío Gonzáles y Begonya Saez Tajafuerce, Madrid: Trotta, 2000, p. 77 / SKS 1, 65.

${ }^{3}$ Ibíd.

${ }^{4}$ Cfr. Søren Kierkegaard, Sobre el concepto de ironía, p. 275 / SKS 1, 286.

${ }^{5}$ Cfr. Platón, “Apología” en Diálogos I, trad. de J. Calonge Ruiz, E. Lledo Íñigo y C. García Gual, Madrid: Gredos, 1997, 31d-31e.

${ }^{6}$ Cfr. Platón, "Banquete” en Diálogos III, trad. de M. Martínez Hernández, E. Lledo Íñigo y C. García Gual, Madrid: Gredos, 1997, 219a.

${ }^{7}$ Cfr. Platón, “Apología”, 31d; Aristófanes, Las nubes. Las ranas. Pluto, trad. Francisco Rodríguez y Juan Rodríguez, Madrid: Cátedra, 2006, 265.

${ }^{8}$ Cfr. Platón, "Fedón” en Diálogos III, trad. de M. Martínez Hernández, E. Lledo Íñigo y C. García Gual, Madrid: Gredos, 1997, 66a.

${ }^{9}$ Cfr. Søren Kierkegaard, Sobre el concepto de ironía, p. 233 / SKS 1, 243. 
y la idea como posibilidad, se debe a que su consagración a la ironía fue tal que incluso murió a causa de ella ${ }^{10}$.

La tesis XV se desarrolla al final de la disertación en apenas cinco páginas en las que Kierkegaard propone que, así como la duda es el comienzo de la filosofía, la ironía es el comienzo de la vida digna de ser llamada humana. Encontramos que en el texto original, escrito en latín ( $U t$ a dubitatione philosophia sic ab ironia vita digna, qux bumana vocetur, incipit), y en la versión danesa traducida por lo editores de los SKS (Ligesom filosofien begynder med tvivl, således begynder et liv, der fortjener at kaldes menneskeligt, med Ironi) ${ }^{11}$, los términos que en castellano son traducidos por "comienzo" son incipit y begynder, con los cuales se podría entender que la ironía es el comienzo de

${ }^{10}$ Pese a que Sócrates no alcanzara la idea, al dar lugar al despertar de la subjetividad, la ironía socrática, según Hegel, adquiere una justificación en la historia del pensamiento humano. Lo que históricamente se observa es que, al negar el fundamento, el orden establecido y todo lo demás propio de la sustancialidad helenista, Sócrates ofrece una nada que contiene un conjunto infinito de posibilidades, las cuales, si bien no son tomadas y llevadas a cabo por Sócrates, muchas de ellas son desarrolladas por las conocidas escuelas socráticas. Al moverse entre la negación y la posibilidad, Sócrates representa el punto de inflexión histórico necesario para dejar atrás una época y dar lugar a una nueva. Kierkegaard se muestra partidario de esta consideración hegeliana, pero no es casualidad que el análisis que se propone hacer en su disertación se haga, en principio, con referencia a un individuo, Sócrates, y que posteriormente su análisis del concepto se haga con referencia a la forma de vida propuesta por la ironía de los románticos, conforme a este modo de proceder, su análisis parece estar más orientado a evidenciar la justificación que la ironía tiene en el plano existencial. Con tal análisis del concepto de ironía, Kierkegaard nos muestra que la ironía, lejos de ser una simple figura retórica, es en un modo de vivir en que, dicho de manera general, se rechaza la verdad establecida para ir en búsqueda de una verdad a partir de la propia subjetividad. De esta manera, la ironía aparece como un modo de repensar la existencia, de ser libre de verdades impuestas y poder asumir nuevas verdades desde y para la existencia. Kierkegaard mismo nos deja ver que para él la ironía no sólo fue un tema académico con el que obtuviera su título de Magister Artium, el asumió personalmente la ironía como su modo de vivir y como la forma de comunicarse a su lector. En Mi punto de vista, vemos que Kierkegaard explica que su objetivo como escritor religioso era rechazar la cristiandad como una verdad que en su época se asumía sin un verdadero compromiso, su deber era mostrarle a su lector que este no era el cristiano que decía ser -el lector, cual discípulo socrático, no sabía lo que creía saber-. Al obligarle a su lector a darse cuenta de ello, le obligaba a juzgar (Søren Kierkegaard, mi punto de vista, p. 64); es decir, le obligaba a ir a su interior, para que fuera a partir de la propia subjetividad que el lector se relacionara con la verdad del cristianismo, de tal suerte que esta no fuera una verdad ajena, sino una verdad personal. No obstante, Kierkegaard no creía que él ya hubiera terminado la tarea de hacerse un verdadero cristiano, sino que reconoce que en el proceso de ayudar a su lector a serlo, él mismo estaba siendo educado (mi punto de vista, p. 133).

${ }^{11}$ SKS 1, 65.2, nota. 
la vida humana en un sentido temporal. No obstante, en el desarrollo de esta tesis encontramos que Kierkegaard sostiene que: "así como los hombres de ciencia afirman que la ciencia verdadera no es posible sin la duda, así también y con el mismo derecho podríamos afirmar que la vida genuinamente humana no es posible sin la ironía"12. Con base en este pasaje y en otros que serán señalados a lo largo de este texto, debemos considerar que lo que la tesis XV nos señala es que la ironía y la duda son comienzo, no en un sentido temporal, sino causal de la vida humana y de la filosofía, respectivamente.

Ahora bien, mientras la tesis XV nos habla de una ironía dominada, la tesis IV nos habla de una vida entregada sin límite a la ironía. A primera vista, la información suministrada por dichas tesis podría indicar que, dada la carencia de un límite, la ironía socrática no podría ser el principio causal de la vida humana. El propósito del presente texto es elucidar hasta qué punto ambas tesis son compatibles, es decir, hasta qué punto la ironía socrática podría ser una ironía dominada que constituya una forma de vida. Para el cumplimiento del propósito señalado dividiré el texto en dos secciones. En la primera examinaré con detalle la tesis XV; en la segunda, examinaré, apoyándome en algunas consideraciones de Pierre Hadot, si la ironía socrática puede ser considerada el comienzo de la vida digna de ser llamada humana, pese a la dificultad que nos plantea la tesis IV.

\section{Asi como la filosofía comienza con la duda, la vida digna de ser llamada bumana comienza con la ironía}

La analogía propuesta por Kierkegaard nos muestra que hay algo común entre la duda y la ironía, a saber, que ambas son comienzo. Pero más allá de lo planteado en esta tesis, podemos ver que en varios pasajes de Sobre el concepto de ironía Kierkegaard explica una aludiendo a la otra. Partiré entonces de la mención y análisis de dichos pasajes con el fin de dar luz sobre la analogía que en la tesis XV Kierkegaard nos plantea entre la ironía y la duda, y la relación que respectivamente estas tienen con la filosofía y la vida digna de ser llamada humana.

\section{A. La relación entre la duda y la ironía}

La primera mención en la disertación de Kierkegaard sobre la relación entre la duda y la ironía la encontramos en la sección "La concepción se hace

${ }^{12}$ Søren Kierkegaard, Sobre el concepto de ironía, p. 339 / SKS 1, 255; cursiva mía. 
real" 13 , perteneciente a la primera parte de la disertación "La posición de Sócrates concebida como ironía”. Aquí, Kierkegaard distingue entre la ironía ideal que es solo un momento pasajero dentro del sistema y la ironía como posición, la cual, como cualquier posición de vida, está sujeta a los vaivenes de la existencia. De manera semejante, señala que la duda en el sistema solo es un momento pasajero, pero en la realidad la duda está constantemente presente para doblegar y destruir lo que se alce contra ella ${ }^{14}$. Este primer pasaje muestra que tanto la ironía como la duda pueden ser concebidas fuera de su relación con el sistema y como parte de la existencia, en donde ambas son posiciones de vida.

La siguiente mención la encontramos en la segunda parte de Sobre el concepto de ironía, en la que Kierkegaard inicia dando una serie de orientaciones para entender el concepto. Al explicar la distinción entre la ironía retórica y una ironía pura o ironía como posición, Kierkegaard alude a la diferencia cualitativa que hay entre una duda vulgar [vulgær Tvivl] y la duda especulativa [spekulativ Tvivl] ${ }^{15}$. Aunque no ofrece mayor detalle sobre esta distinción, afirma que a partir de la duda vulgar se pueden considerar algunos rasgos de la especulativa. De ahí que en estas orientaciones parta de la ironía retórica para ofrecer rasgos característicos de la ironía pura.

La tercera mención se da nuevamente en la sección de Orientaciones, en donde Kierkegaard señala que en virtud de la negatividad absoluta que ambas expresan, la ironía podría confundirse con la duda. No obstante, aclara,

(...) por una parte, que la duda es una determinación conceptual, y la ironía un ser-para-sí de la subjetividad, y que, por otra parte, la ironía es esencialmente práctica (...) En la duda el sujeto está siempre queriendo acceder al objeto, y su desgracia es que el objeto está siempre escapándosele. En la ironía el sujeto está siempre queriendo apartarse del objeto (...) En la duda, el sujeto es testigo de una guerra de conquista en la que todos los fenómenos son aniquilados, puesto que se supone que la esencia está siempre detrás de los mismos. En la ironía, el sujeto está siempre retrocediendo, impugna la realidad de cada fenómeno a fin de salvarse a sí mismo, es decir, a fin de preservarse él mismo en la negativa independencia respecto de todo ${ }^{16}$.

\footnotetext{
${ }^{13}$ Cfr. Søren Kierkegaard, Sobre el concepto de ironía, pp. 201 / SKS 1, 207.

${ }^{14}$ Cfr. Søren Kierkegaard, Sobre el concepto de ironía, pp. 208-209 / SKS 1, 215.

${ }^{15}$ Cfr. Søren Kierkegaard, Sobre el concepto de ironía, pp. 275, 281 / SKS 1, 286, 292.

${ }^{16}$ Søren Kierkegaard, Sobre el concepto de ironia, p. 284 / SKS 1, 295-296.
} 
Es importante notar que hay una semejanza que podría hacer que alguien confundiera la ironía con la duda, a saber, que ambas son absolutamente negativas, que niegan el fenómeno en virtud de la esencia y, que en este sentido, muestran la oposición entre lo uno y lo otro, entre lo externo y lo interno. Pero cada una se mueve en un plano diferente; mientras la ironía se mueve en el plano de la existencia, de la subjetividad, de la práctica y de la libertad del sujeto, la duda se mueve en el plano conceptual, teorético, científico y especulativo. La relación que se traza en este pasaje entre la ironía y la duda marca, por una parte, una posible ruptura con la consideración del primer pasaje señalado, en el que tanto la ironía como la duda son concebidas fuera del sistema y como posiciones de vida; por otra parte, concebir la duda como una determinación conceptual nos conduce a la relación entre duda y filosofía que en la tesis XV Kierkegaard nos plantea. Pasemos a examinar esta.

La tesis XV, expuesta en la sección final titulada "La ironía como elemento dominado", expresa que "aquello que la duda es para la ciencia, la ironía lo es para la vida personal" ${ }^{17}$. En las notas de la traducción al castellano ${ }^{18}$ hecha por Darío González, encontramos que la relación entre duda y filosofía fue probablemente tomada por Kierkegaard de la reseña que Martensen hace del texto de Heiberg "Lección introductoria para el curso de lógica para principiantes de noviembre de 1834 en el Real colegio militar" [Indledningsforedrag til det $i$ November 1834 begyndte logiske Cursus paa den kongelige militaire Høiskole]. En esta reseña, Martensen hace énfasis en el papel de la duda en la filosofía sistemática desde Descartes hasta Hegel.

Recordemos que fue Descartes quien, queriendo seguir la razón para hallar la verdad en las ciencias, implementó un método que tenía por primer precepto: "No admitir como verdadera cosa alguna, como no supiese con evidencia que lo es; es decir, evitar cuidadosamente la precipitación y la prevención, y no comprender en mis juicios nada más que lo que se presentase tan clara y distintamente a mí espíritu, que no hubiese ninguna ocasión de ponerlo en duda" 19 .

Es evidente que esta idea cartesiana es la que en su reseña Martensen expresa: "La duda es el comienzo de la sabiduría. A través de esta duda se busca un punto de vista del que ya no sea posible dudar, una certeza [Viis-

${ }^{17}$ Søren Kierkegaard, Sobre el concepto de ironia, p. 339 / SKS 1, 355.

${ }^{18}$ Cfr. Søren Kierkegaard, Sobre el concepto de ironía, nota 522.

${ }^{19}$ René Descartes, "Discours de la méthode”, en Oeuvres et Lettres. París: Gallimard, 1953, p. 19. 
hed] que ya no es diferente de la verdad [Sandheden] misma"20. Pese a la disputa entre Kierkegaard y Martensen, hay evidencias de que Kierkegaard asistió a muchas de las clases de Martensen, leyó sus textos y cuidadosamente tomó apuntes de sus lecciones. En lo que respecta al conocimiento que Kierkegaard pudo tener de la citada reseña, la evidencia más clara que se encuentra es la semejanza entre muchas afirmaciones de esta reseña y fragmentos del drama La disputa entre la vieja y la nueva jabonería $a^{21}$. Aunque este drama maneja un tono satírico, es plausible que la sátira esté dirigida a Martensen y no a las ideas que este expresó en su reseña ${ }^{22}$. De ahí que, pese a las diferencias personales, el joven Kierkegaard adoptara para su disertación la sentencia "la duda es el comienzo de la sabiduría o filosofía (sistemática)".

La idea que acompañó a la filosofía sistemática desde Descartes hasta Hegel estableció que la duda podía depurar a las ciencias de toda falsedad permitiendo hallar una verdad certera, es decir, libre de cualquier duda. El método de esta filosofía consistió entonces en pasar toda verdad establecida por el filtro de la duda hasta obtener la certeza. Como Martensen lo expresó en su reseña: la ciencia exigió la duda absoluta e infinita ${ }^{23}$. Estas palabras las encontramos en la disertación de Kierkegaard referidas a la ironía socráti$\mathrm{Ca}^{24}$. Esto nos permite considerar que tanto la ironía como la duda se alzan con su poder negativo sobre toda la realidad —lo cual las hace infinitamente negativas- y que niegan la realidad en virtud de algo superior que, no obstante, no es alcanzado por ninguna de ellas - lo cual las hace absolutamente negativas ${ }^{25}$. Si seguimos a Kierkegaard en su analogía, la ironía debe desempeñar entonces una labor similar a la de la duda, no en la filosofía, sino en la vida personal.

Dado que explícitamente encontramos la analogía expuesta en la última parte de la disertación: "la ironía como elemento dominado", será pre-

${ }^{20}$ Hans Martensen, "Indledningsforedrag til det i November 1834 begyndte logiske Cursus paa den kongelige militaire Høiskole. Af J. L. Heiberg, Lærer i Logik og Æsthetik ved den kgl. Militaire Høiskole”, en Maanedskrift for Litteratur, no. 16, 1836, p. 517.

${ }^{21}$ Cfr. Søren Kierkegaard, Primeros diarios, vol. II, trad. de María Binetti, México: UIA, 2012, p. 175.

${ }^{22}$ Jon Stewart, Kierkegaard's Relations to Hegel Reconsidered, Nueva York: Cambridge University Press, 2003, p. 114.

${ }^{23}$ Hans Martensen, "Indledningsforedrag til det i November 1834 begyndte logiske Cursus", p. 519.

${ }^{24}$ Cfr. Søren Kierkegaard, Sobre el concepto de ironía, pp. 287 / SKS 1, 299.

${ }^{25}$ Ibíd. 
ciso dirigirnos a ella y analizarla a fin de tener mayor claridad sobre lo que aquí nos interesa saber: cómo la ironía hace posible la vida digna de ser llamada humana.

\section{B. Ironía como elemento dominado ${ }^{26}$}

Como se mencionó, Kierkegaard caracteriza la ironía socrática como una negación de la verdad establecida que le permite al ironista la búsqueda de la verdad a partir de la propia subjetividad. Luego de la descripción de esta primera ironía, Kierkegaard describe la ironía romántica, en la cual la subjetividad es potenciada de manera tal que el ironista se toma la libertad desmedida, no solo de negar y destruir, sino también de crear, para finalmente destruir todo sin fundamento alguno. Tras este recorrido por la caracterización del concepto de ironía en la historia, Kierkegaard concluye su disertación hablándonos del poeta que consigue dominar la ironía, logrando, a través de esta, liberar tanto al poema como a sí mismo. Este poeta solo vive realmente de manera poética cuando en la libertad que la ironía le ha otorgado no niega toda su realidad, sino que se reconcilia con esta ${ }^{27}$. Para que finalmente haya una reconciliación entre el ironista y la realidad, la ironía no puede destruir de manera desmedida todo lo que se encuentra a su paso, en otras palabras, esta debe ser dominada.

Al ser dominada, la ironía resulta indispensable para la vida humana, pues quien carece de ella:

(...) carece de ese baño renovador y rejuvenecedor, de ese bautismo purificador de la ironía que redime al alma de su vida en lo finito, por más que esa vida sea intensa y vigorosa; no sabe cuán refrescante y reconfortante es, cuando el aire se torna demasiado opresivo, desvestirse y lanzarse al mar de la ironía, no para permanecer en él, naturalmente, sino para volver a vestirse indemne, ligero y satisfecho ${ }^{28}$.

${ }^{26}$ He decidido modificar ligeramente la traducción hecha por Darío González, dado que la versión danesa Ironi som behersket Moment es probablemente mejor traducida como "ironía como elemento dominado" o "ironía como factor dominado". Con este cambio, se rechaza la connotación temporal que tiene la palabra "momento" en castellano y, que haría entender la ironía como un determinado periodo que antecede en el tiempo a la vida humana y que puede ser definitivamente abandonado una vez se ha pasado por él.

${ }^{27}$ Cfr. Søren Kierkegaard, Sobre el concepto de ironía, p. 338 / SKS 1, 354.

${ }^{28}$ Søren Kierkegaard, Sobre el concepto de ironía, p. 339 / SKS 1, 355; cursiva mía. 
De manera que, así como la duda depura a la ciencia de la falsedad, la ironía depura a la vida humana de lo finito y opresivo. Pero esta depuración no implica una vida de completo rechazo o aislamiento de lo finito. Kierkegaard señala que, por el contrario, la ironía se muestra en su verdad cuando ayuda al individuo a reconciliarse con su realidad, no a costa de perder el anhelo por un ideal o por algo superior a la realidad, sino al hacer la realidad una parte de ese ideal.

La ironía dominada que Kierkegaard propone posee un aspecto correctivo y liberador que ayuda al individuo a ver lo que hay de incorrecto en la realidad y a liberarse de esta para poder perseguir su ideal. Pero asimismo evita un exceso de libertad que haga que el individuo se pierda en el ideal y no pueda regresar a la realidad. La ironía dominada hace que el individuo identifique lo erróneo del fenómeno, de lo establecido y de lo finito, y busque corregirlo teniendo como base y límite la Idea. Aplicada de manera limitada, la ironía es el camino por el que el individuo se libera de lo erróneo de la realidad y se dirige a lo ideal, para alcanzarlo y desarrollarlo en la realidad misma. Es preciso aclarar que, al ser dominada la ironía, no pierde su carácter negativo ni adquiere uno positivo; la ironía dominada

(...) deja de creer que (...) hay siempre algo detrás de las apariencias; pero evita también toda idolatría del fenómeno y, así como enseña a respetar la contemplación, así también nos dispensa de la prolijidad que consiste en pensar, por ejemplo, que una exposición de la historia universal requeriría un tiempo tan largo como el que el universo tardó en vivirla ${ }^{29}$.

Que el individuo deba dominar la ironía significa entonces que no puede tener una vida por completo entregada a ella. Puede sumergirse en el mar de la ironía, pero no permanecer en él. Permanecer en la ironía implica un peligro análogo al del filósofo o científico que permanece en la duda. Abordaré esto con mayor detalle, apoyándome en la crítica que Kierkegaard hace a la sentencia "es necesario dudar de todo" en su obra De omnibus dubitandum est.

${ }^{29}$ Søren Kierkegaard, Sobre el concepto de ironia, p. 341 / SKS 1, 357. 


\section{La duda de Climacus y la ironía socrática}

En los años siguientes a la entrega de la disertación, Kierkegaard escribe De omnibus dubitandum est (1842-1843). En este texto, el joven Johannes Climacus $^{30}$, con el ánimo de aprender a filosofar, reflexiona sobre tres tesis principales que había escuchado de los filósofos en más de una ocasión. Estas son: "1. La filosofía comienza con la duda. 2. Uno debe haber dudado para poder filosofar. 3. La filosofía moderna comienza con la duda" ${ }^{31}$. Al proseguir con el análisis de cada una de las tesis, Johannes empieza a notar algunas incongruencias entre ellas. Por ejemplo, observa que en la tesis (1) se afirma que la duda es el comienzo de la filosofía, lo cual expresa una sentencia eterna, mientras que en la tesis (3) se expone que la duda es el comienzo de la filosofía moderna, lo cual es una sentencia histórica ${ }^{32}$. Si la filosofía moderna se tiene por la única o esencial filosofía, entonces se podría eliminar la confusión entre categorías (histórica y eterna), pero, al hacer esto, la tesis (3) se haría idéntica a la tesis (1). Esto último negaría además la existencia de una filosofía antigua o habría que asumir que hay otro comienzo distinto a la duda que dio origen a dicha filosofía. Johannes empieza a cuestionar qué había determinado que la filosofía comenzara con la duda, si se trataría de algo accidental o necesario. Al pasar a la tesis (2), advierte que esta expresaba algo distinto a las otras, pues no ponía a la duda como el comienzo de la filosofía, sino que ponía a la duda como algo anterior al comenzar a filosofar ${ }^{33}$. Además, se pregunta si la sentencia "hay que dudar para comenzar a filosofar" al ser transmitida no haría que quien la recibiera dudara de la sentencia misma ${ }^{34}$.

Enfocado en su anhelo por empezar a filosofar, abandona el análisis poco fructífero sobre las tesis y pasa a reflexionar sobre la relación que él, o cualquier otro individuo, tiene con tales tesis. Comienza entonces a cuestionar si para formular la sentencia "De omnibus dubitandum est" tendría que tener algún especial talento o autoridad, o si bastaría con creer en el primero que había formulado dicha tesis, aunque en este caso el comienzo de la filosofía para él no sería la duda, sino el creer que alguien ya ha dudado ${ }^{35}$.

${ }^{30}$ Posiblemente sea una referencia al monje bizantino Juan Clímaco (525-616, aprox.), Ioannes Climacus, quien fue abad del monasterio de Santa Catalina en el Monte Sinaí.

31 SKS 15, 27. Traducción al castellano de F. Nassim Bravo.

${ }^{32}$ Cfr. SKS 15, 37. Traducción al castellano de F. Nassim Bravo.

${ }^{33}$ Cfr. Ibíd.

${ }^{34}$ Cfr. SKS 15, 38. Trad. de F. Nassim Bravo.

${ }^{35}$ Cfr. SKS 15, 44. Trad. de F. Nassim Bravo. 
Prosiguiendo, se pregunta si, dado que alguien más ya dudó, la duda de él sería una nueva duda o una adición a la primera, si tendría que creer en lo que el otro ya dudó o debería dudar también sobre cómo aquél lo hizo ${ }^{36}$. Entre más reflexionaba, Johannes se sentía más alejado de la filosofía:
(...) fuera cual fuere el significado de esta sentencia y su relación con la filosofía, Johannes se daba cuenta muy bien de que este era un co- mienzo con el que uno quedaba fuera de la filosofía, ya se admitiera que la filosofía realmente persistía a pesar de que el individuo queda- ba excluido de ella a causa de su comienzo, ya se admitiera que este comienzo destruía a la filosofía, con lo cual a uno le resultaría también imposible acceder a ella ${ }^{37}$.

A partir de este breve resumen de De Omnibus, podemos ver cómo Kierkegaard retoma en esta obra la sentencia que había marcado la filosofía moderna y que Martensen había hecho popular en Dinamarca. Pero, mientras en Sobre el concepto de ironía la usa para explicar una de las tesis más importantes de su disertación, en De Omnibus la critica mostrando el absurdo al que conduce. Ahora bien, por distinto que pueda parecer el uso que Kierkegaard hace de la sentencia en estas dos obras, la crítica que hace de ella en De Omnibus podría ser aplicada a la ironía en El concepto de ironía. Luego, la analogía entre la duda y la ironía también podría mantenerse en este sentido, que si bien ambas hacen posible la filosofía y la vida personal, respectivamente, también ambas podrían ser la destrucción de la filosofía y de la vida humana. En el caso de la duda, esto último ocurre cuando, como se muestra en De omnibus, el dudar no está delimitado y podría nunca tener fin. A la luz de este texto y de la analogía que aquí se ha expuesto entre la duda y la ironía, considero que lo que Kierkegaard nos dice en su disertación es que la ironía sin límites también podría presentar el problema que presenta el dudar sin límites. De manera que, cuando la ironía no tiene un límite, contrario a ser el principio la vida digna de ser llamada humana, podría ser el fin de esta.

Con todo, el análisis de la analogía entre la duda y la ironía nos ha permitido encontrar semejanzas que definen a ambas en su negatividad y que señalan que ambas deben ser limitadas, porque, de lo contrario, lejos de hacer posible la filosofía y la vida personal, serían el fin de estas. También ha

\footnotetext{
${ }^{36}$ Cfr. SKS 15, 46. Trad. de F. Nassim Bravo.

37 SKS 15, 42. Trad. de F. Nassim Bravo.
} 
sido posible observar que, en el caso de la ironía, cuando es dominada, renueva, purifica y redime la vida humana. No obstante, aún no es claro cómo la ironía con su negatividad puede ser el principio de la vida digna de ser llamada humana; si la ironía implica la negación de la realidad, cómo puede permitirle al individuo reconciliarse con ella. A fin de dar respuesta a la cuestión planteada, y sin abandonar la relación entre la ironía y la duda, me dirigiré a una conocida entrada de los diarios de Kierkegaard sobre su viaje a Gilleleje (1835), en la que la exposición sobre la duda de Fausto podría dar luz sobre la forma en la que ironía dominada actúa en la vida personal.

\section{La duda de Fausto y la ironía}

En marzo de 1835, tras haber leído la extensa bibliografía que Stieglitz había proporcionado sobre $\mathrm{Fausto}^{38}$, Kierkegaard inicia su propio proyecto acerca del nigromante alemán, mismo que, dos años después, se ve interrumpido por la publicación de Martensen sobre el Fausto de Lenau en Perseus ${ }^{39}$. De forma parecida a lo expuesto por Martensen, Kierkegaard consideraba a Fausto como la personificación de la duda. Esta tesis la encontramos en una presunta carta dirigida a Lund fechada el 1 de junio de $1835^{40}$, días antes de la llegada de Kierkegaard a Gilleleje. En dicha carta, Kierkegaard afirma que, poco después de que Fausto, con independencia de Dios, decidiera ir en busca de la más alta iluminación, se da cuenta de que ni el mundo ni Mefistófeles pudieron ofrecerle tal iluminación, pues esta era una iluminación divina. De manera que, con sus ojos puestos en su ideal, Fausto duda de la sabiduría humana o de cualquier otra sabiduría que el diablo pudiera otorgarle. Este rechazo del mundo por no proporcionar lo que el individuo requiere se observa claramente en la ironía. Kierkegaard señala esta similitud en otra entrada de sus diarios:

Fausto debería ser puesto en paralelo con Sócrates. En efecto, así como este último expresa la separación del individuo con respecto

${ }^{38}$ En 1834, Christian Ludwig Stieglitz (1756-1836) escribió "La leyenda del Doctor Fausto [Die Sage vom Doctor Faust]" en el Manual histórico [Historisches Taschenbuch] de Friedrich von Raumer; al final de este ensayo adicionó una larga bibliografía sobre Fausto.

${ }^{39}$ En junio de 1837, Martensen publica "Reflexiones sobre la idea de Fausto. Con referencia al Fausto de Lenau [Betragtninger over Ideen af Faust. Med Hensyn paa Lenaus Faust]" en Perseus, revista editada por Heiberg.

${ }^{40}$ Cfr. Søren Kierkegaard, Primeros diarios, vol. I, trad. de María Binetti. México: UIA, 2011, p. 73. 
al Estado, así también Fausto, después de la disolución de la Iglesia, expresa al individuo separado de su guía y abandonado a sí mismo, cosa que indica su relación con la Reforma y que parodia la Reforma, acentuando unilateralmente su lado negativo ${ }^{41}$.

Continuando con la entrada sobre la carta a Lund, se puede observar que la referencia de Kierkegaard a Fausto tiene lugar dadas las circunstancias por las que él mismo está atravesando. Al igual que Fausto, Kierkegaard desea ir en busca de su ideal, de su destino. Reconoce que hay un grupo de personas que están inclinadas a ir por una determinada senda y nunca son disuadidos de un cambio, mientras hay otras que se dejan conducir por lo exterior y no tienen una meta definida ${ }^{42}$. Kierkegaard manifiesta querer ser parte del primer grupo, aun cuando no tiene su ideal definido, el cual busca en dos de sus principales intereses: las ciencias y la teología. No obstante, a medida que expone su interés en ellas, también muestra las dudas que tiene sobre cada una. Kierkegaard se encuentra viviendo el problema fáustico, pues ni las ciencias ni la teología satisfacen la búsqueda por un ideal que guie su vida.

Dos meses después de la carta a Lund, Kierkegaard escribe el 1 de Agosto de 1835 desde Gilleleje:

Tal como intenté mostrar en lo anterior, así veía yo las cosas. Sin embargo, cuando quiero poner en claro mi vida, todo me parece de otra manera. [...] lo que necesito es ver con claridad qué debo hacer y no qué debo conocer, a no ser en la medida en la que el conocimiento debe preceder cualquier acción. Se trata de entender mi destino, de ver lo que la divinidad quiere que haga. Lo que importa es encontrar una verdad que sea verdad para mí, encontrar esa idea por la cual querer vivir y morir. [...] no negaré que yo presupongo un imperativo del conocimiento, a través del cual es posible actuar sobre los hombres, pero para eso es necesario asumirlo vitalmente, y esto es lo que considero esencial ${ }^{43}$.

Un camino de búsqueda fallido — la duda es la que revela el fracaso- le permite a Kierkegaard hacer un cambio de mirada. Deja entonces de buscar en el conocimiento para buscar en la práctica; deja de buscar en lo externo

\footnotetext{
${ }^{41}$ Søren Kierkegaard, Primeros diarios, vol. II., p. 66.

${ }^{42}$ Cfr. Søren Kierkegaard, Primeros diarios, vol. I, p. 73

${ }^{43}$ Søren Kierkegaard, Primeros diarios, vol. I., p. 80.
} 
para buscar a través de su interior aquel ideal por el cual vivir y morir. Se da cuenta de que lo que ha de regir su vida no puede ser un conocimiento objetivo ajeno a sí mismo, aunque tampoco una verdad subjetiva-arbitraria. De lo que se trata es de buscar una verdad de la cual él pueda apropiarse.

En este proceso de encontrar un ideal, la duda aparece como el camino a través del cual es posible deshacerse de aquellos medios por los cuales no podría alcanzarse un verdadero ideal para la vida. Como Kierkegaard lo expresa, Fausto debe ser equiparado con Sócrates, pues ambos separan al individuo de aquello que impide su realización. La duda y la ironía representan un camino que, sin un límite, puede conducir a la destrucción de un individuo ${ }^{44}$, pero un camino que, limitado, despeja el terreno de toda verdad impuesta y ajena al individuo para que este se dirija a su interior y busque por sí mismo la verdad que sea verdad para él. La ironía, como la duda, permite dos aspectos importantes del desarrollo de la personalidad. Por un lado, ayuda al individuo a reflexionar en torno a lo dado y aceptado inconscientemente, a reevaluarlo y a rechazarlo, para que, por otro lado, el individuo pueda ir en pos de su ideal, el cual asume vitalmente, es decir, sin abandonar su vida dada en cierta época y lugar. En otras palabras, la ironía permite tanto la desvinculación como la reconciliación con la realidad; una reconciliación en la que el individuo se dirige a su realidad haciéndola parte de su ideal, el cual, a su vez, es la guía (el impulso y el límite) para poder realizarse en dicha realidad. Kierkegaard da claridad sobre este punto ejemplificándolo con la vida del cristiano (protestante), el cual, teniendo por ideal la salvación, no busca purificar su alma en un purgatorio, lejos de los vaivenes de la vida terrenal, sino que realiza su vida finita y terrena acorde al ideal que guía su vida ${ }^{45}$.

El análisis del paralelo que aquí se ha hecho entre la duda y la ironía muestra la necesidad de un límite que restrinja el poder negativo que ambas poseen. Queda claro que, al ser dominada, la ironía desempeña un papel esencial en la vida humana, pues le permite al individuo liberarse de toda opresión o vía errónea que impida el encontrar un ideal para la vida, sin que tal liberación implique un huir de la realidad en la que vive. Ahora bien, cuando Kierkegaard habla en su disertación sobre la ironía dominada, no hace mención alguna de si esta ironía es o puede ser la socrática o la romántica, trabajadas ampliamente a lo largo del texto. El objetivo de la siguiente

${ }^{44}$ El Fausto de Lenau es muestra de esto, pues su duda crece de tal forma que, ahogado en la desesperación, termina suicidándose.

${ }^{45}$ Cfr. Søren Kierkegaard, Sobre el concepto de ironía, p. 341 / SKS 1, 357. 
sección será mostrar que la ironía propuesta por Sócrates es la ironía que, al dominarse, puede constituir una forma de vida.

\section{Ironía socrática como forma de vida}

La ironía carente de límites se presenta en la disertación de Kierkegaard en dos casos diferentes. Por un lado, con Sócrates, quien "no solo utilizó la ironía, sino que además se consagró a la ironía hasta el punto de sucumbir a ella" (tesis IV); y, por otro lado, con la ironía de los románticos, quienes con una subjetividad potenciada se convirtieron en creadores y destructores de sí mismos. ${ }^{46}$ Aunque para nuestros fines la ironía socrática es el centro de nuestro interés, creo pertinente hacer explícitas algunas diferencias que hay entre esta y la ironía de los románticos, en lo que respecta a la carencia de un límite.

La primera diferencia que encontramos es que, mientras la ironía que se da con Sócrates se da en contra de la realidad de este, es decir, la realidad dada en cierto tiempo y lugar, la ironía de los románticos niega toda realidad, la del presente, la pasada y la futura, pues aspira a una realidad metafísica que no puede darse en el tiempo ${ }^{47}$. En el caso de la ironía socrática, la negación deja un terreno llano desde el cual Sócrates divisa el límite externo de la Idea, es decir, que esta se le presenta a Sócrates como posibilidad. En la ironía romántica nunca se presenta la Idea, solo hay deseos y sentimientos mutables en virtud de los cuales se configuran realidades ubique et nusquam. La carencia de límites en el caso de Sócrates se da en la forma en que este llevó a cabo su ironía, en otras palabras, su entrega a la ironía es la que carece de límites, hasta el punto de terminar sucumbiendo a ella. En el caso de los románticos, la carencia de límites está en la infinita y absoluta negatividad de su ironía y en la subjetividad potenciada que se sigue de tal negatividad.

En cualquiera de estos casos la exigencia de un límite se hace necesaria. Pues, ya sea porque una vez entrados en el mar de la ironía deseemos permanecer en él —como Sócrates lo hizo, y era menester que lo hiciera- o porque este mar tenga tanta potencia que sea imposible salir de él —como fue el caso de la ironía romántica-, la reconciliación con la realidad sería imposible, y se viviría una vida de absoluta e infinita negatividad.

\footnotetext{
${ }^{46}$ Cfr. Søren Kierkegaard, Sobre el concepto de ironía, p. 304-305 / SKS 1, 318-319.

${ }^{47}$ Cfr. Søren Kierkegaard, Sobre el concepto de ironía, p. 301 / SKS 1, 314.
} 
Teniendo en cuenta las diferencias antes señaladas entre la ironía socrática y la romántica, considero que es la primera la que, al ser dominada, es el comienzo de una vida digna de ser llamada humana. En lo que sigue defenderé este planteamiento acudiendo, en principio, al análisis que Hadot hace de la filosofía antigua como forma de vida y a su análisis específico de la filosofía socrática.

\section{A. La filosofía antigua como forma de vida}

Arnold I. Davidson señala que, en su análisis de la filosofía antigua, Pierre Hadot afirma que toda ella "supone un ejercicio espiritual puesto que constituye un modo de vivir, una forma de vida, una elección vital"48. Hadot explica que, refiriéndose a la filosofía antigua, "ejercicio espiritual" significa la práctica o actividad del espíritu, pensamiento, voluntad, imaginación y sensibilidad $^{49}$. En este sentido, la filosofía antigua resulta siendo una práctica que involucra todo el ser, algo que lo modifica y lo transforma. Con su interpretación, Hadot distingue al filósofo antiguo del sabio (sophos) o del filósofo que se forma a partir de la Edad Media, el cual es un individuo proveedor de conceptos, teorías y doctrinas ${ }^{50}$. Contrario a esto, el filósofo antiguo provee, más que un discurso o una doctrina, una práctica. En el caso de Sócrates, particularmente, quien no dejó registro escrito de sus discursos y conversaciones, lo que nos deja a la posteridad es su modo de vivir.

Es necesario añadir que, según esta interpretación, la forma de vida que se da con la filosofía antigua no se trata de cualquier forma de vida, sino de un modo de vivir que mejora y hace feliz a quien practica la filosofía, pues con ella se da el paso de la no consciencia y preocupación (por cosas que no dependen de nosotros) a la consciencia de sí mismo y a la libertad ${ }^{51}$. Hadot hace un breve recorrido desde Sócrates hasta Plotino, pasando por Platón, estoicos, epicúreos, etcétera, para mostrarnos cómo la propuesta filosófica de estos constituyó una práctica de realización y mejora del individuo. Aunque mi interés está puesto en Sócrates, antes de detenerme en las consideraciones que Hadot hace del filósofo ateniense, expondré bre-

${ }^{48}$ Pierre Hadot, Ejercicios espirituales y filosofía antigua, trad. de Javier Palacio, Madrid: Ediciones Siruela, 2006, p. 1.

${ }^{49}$ Cfr. Ibíd.

${ }^{50}$ Cfr. P. Hadot, Ejercicios espirituales y filosofía antigua, p. 35.

${ }^{51}$ Cfr. P. Hadot, Ejercicios espirituales y filosofía antigua, p. 25. 
vemente su caracterización general de la forma de vida propuesta por la filosofía antigua.

A fin de tener un bosquejo claro de la forma de vida de los filósofos antiguos, expondré la caracterización que Hadot nos ofrece en tres etapas. La primera es una fase de superación o negación de las pasiones, las cuales son la causa principal del sufrimiento del hombre, pues hacen que se preocupe o desee de manera desmedida aquello que no depende de él. Aunque en esta etapa cada escuela tiene su propia terapia, el fin resulta el mismo: un distanciamiento de la cotidianidad ${ }^{52}$, de los prejuicios y las convenciones sociales. ${ }^{53}$ La segunda fase es el cambio de perspectiva en el que se invierten los valores e intereses: dejan de importar los valores aceptados, los honores y riquezas, y comienza el interés por sí mismo, por reconocerse consciente y libre dentro del Todo. Y la tercera y última etapa es la búsqueda de la verdad por sí mismo, la elevación del espíritu al pensamiento puro, especulativo o pensamiento del Todo ${ }^{54}$.

En lo que respecta a Sócrates, Hadot presenta la filosofía socrática como un ejercicio espiritual y, en este sentido, como una forma de vida en la que podemos observar rasgos del esquema anterior y del fin general al que se dirige la filosofía como forma de vida. Por ejemplo, respecto al diálogo socrático, Hadot señala que, mediante este, el interlocutor es conducido a cuestionar lo que tenía por dado, su manera de vivir y el fundamento de sus actos; tras este cuestionamiento, se da el interés en el conocimiento de sí mismo y, en este conocimiento, un permitir que el espíritu se eleve ${ }^{55}$. También menciona la actitud de Sócrates frente a la muerte, ${ }^{56}$ la cual consiste en postular un camino de preparación en el que aprender a morir equivale a aprender a vivir, pues prepararse para la muerte consiste en llevar un determinado modo de vida alejado de pasiones, preocupaciones humanas, etcétera.

Pero lo que me ha motivado a traer a colación la interpretación de Hadot es que este describe el lugar que para él la ironía tiene en la filosofía como forma de vida. Basado en el discurso del ebrio Alcibiades, Hadot señala cómo la comparación que aquél hace entre Sócrates y los silenos, hombres que en apariencia no son nada, pero que en su interior albergaban

\footnotetext{
52 Cfr. P. Hadot, Ejercicios espirituales y filosofía antigua, p. 51.

${ }^{53}$ Cfr. P. Hadot, Ejercicios espirituales y filosofía antigua, p. 49.

${ }^{54}$ Cfr. P. Hadot, Ejercicios espirituales y filosofía antigua, p. 45.

${ }^{55}$ Cfr. P. Hadot, Ejercicios espirituales y filosofía antigua, p. 89.

${ }^{56}$ Cfr. P. Hadot, Ejercicios espirituales y filosofía antigua, p. 39.
} 
estatuas de dioses, muestra que Sócrates lleva una máscara y su máscara es la ironía ${ }^{57}$, Sócrates se oculta tras la ironía y finge ser ignorante, se hace inferior a su interlocutor y hace que este se examine a sí mismo y concluya que aquello que creía saber realmente no lo sabe. De manera que en el diálogo con Sócrates el interlocutor termina identificándose con aquél que en apariencia es solo ignorancia:

Al final de la discusión, el interlocutor no ha aprendido nada, por lo tanto, ni siquiera sabe esa nada del todo. Pero durante el tiempo que ha durado la discusión ha experimentado lo que supone la actividad del espíritu, o mejor todavía, se ha convertido en Sócrates, es decir, en su interrogación, su cuestionamiento, su disminución en relación consigo mismo y, finalmente por tanto, en su consciencia ${ }^{58}$.

Aquí Hadot nos muestra que la ironía está presente en la mayéutica socrática; es la que permite que Sócrates, desde la nada de su ignorancia, asista al individuo en el nacimiento de sí mismo. Entendida de esta forma, Hadot equipara la ironía socrática a la comunicación indirecta de Kierkegaard ${ }^{59}$, mediante la cual Kierkegaard no le expone doctrina alguna a su lector, se esconde bajo diversos rostros de los cuales ninguno es verdaderamente el suyo y, con esto, le ayuda al lector a deshacerse del engaño en el que se halla preso. En cuanto a la filosofía socrática considerada como ejercicio espiritual, lo que vendría después del nacimiento de sí mismo es el reconocimiento de sí como una consciencia que es parte de un Todo y que ha de vivir ya no conforme a las pasiones, sino conforme a la razón.

Ahora bien, aunque Hadot en un principio señale que la ironía en Sócrates se da como una máscara con la cual este finge que nada sabe, al desarrollar su estudio ve en dicha declaración de ignorancia algo esencial del ejercicio espiritual propuesto en la filosofía socrática. Hadot pasa a considerar que, cuando Sócrates afirmaba que nada sabía, no se refería a que no poseyera saber alguno, sino a que el saber que poseía no era transmisible por el lenguaje. Y en este caso la ironía socrática aparece como el medio necesario por el cual se puede enseñar algo que no puede ser enseñado directamente: la virtud. Refiriéndonos a un ejemplo que Hadot cita, podemos decir que Sócrates, mediante ${ }^{60}$ la ironía, enseñaba sobre la justicia, pero no

${ }^{57}$ Cfr. P. Hadot, Ejercicios espirituales y filosofía antigua, p. 81.

${ }^{58}$ P. Hadot, Ejercicios espirituales y filosofía antigua, p. 88.

${ }^{59}$ Cfr. P. Hadot, Ejercicios espirituales y filosofía antigua, p. 84.

${ }^{60}$ Cfr. P. Hadot, Ejercicios espirituales y filosofía antigua, p. 89. 
un saber doctrinal, no un saber qué es la justicia, sino un saber vivir con justicia. De ahí que Sócrates afirme: "a falta de palabras, doy a entender lo que es justicia mediante mis actos” ${ }^{1}$.

Lo que entonces Sócrates nos plantea con su ironía no es un fingir ser algo que no es, sino que, en efecto, nos muestra que él no es un sabio, no posee la norma: el Bien, la Belleza, la Justicia, etcétera. Pero como filósofo, es decir, como amante de la sabiduría, nos plantea un camino hacia esta. Este camino es existencial; no es un camino teórico para conocer qué es la Belleza o qué la Justicia — conocimiento que desde luego él no posee-, sino un camino en el que el individuo puede por sí mismo llegar a vivir bellamente, justamente, etcétera. De acuerdo a las consideraciones de Hadot, Sócrates sería una encarnación del Eros que Diotima describe en el Ban$q_{\text {uete }}^{62}$, porque, aunque Eros está carente de aquello que ama —el Bien y la Belleza, siguiendo la naturaleza de Poros, su padre-, pese a ello constituye un pasaje, acceso o salida hacia la Belleza y el Bien. De manera semejante, Sócrates, sin mostrarnos una doctrina de lo Bueno, Bello, etcétera, proporciona la posibilidad para tener una vida buena, bella, justa, etcétera ${ }^{63}$. Luego, el punto central en la filosofía como forma de vida $-\mathrm{y}$ con esto termino la exposición sobre las consideraciones de Hadot— es este: la filosofía no determina una doctrina o sistema en el que se pruebe o se prometa algo, sino que pone sobre la mesa la posibilidad de una vida "más consciente, más racional, más abierta a los otros y a la inmensidad del mundo" ${ }^{64}$.

Si bien la interpretación de Hadot da luz sobre algunos puntos esenciales que permiten considerar la ironía socrática como una forma de vida, es importante marcar cuáles de estos se relacionan con la exposición de Kierkegaard que aquí he seguido. En primer lugar, podemos observar que el diálogo socrático considerado como un ejercicio espiritual en el que el interlocutor renuncia a lo que daba por cierto (su aparente saber) y empieza a conocerse a sí mismo, está estrechamente relacionado con el carácter negativo de la ironía que, como Kierkegaard expone, niega todo principio o fundamento establecido, produciéndose tras ello un cambio de mirada de lo externo a lo interno: a la propia consciencia o subjetividad.

${ }^{61}$ Jenofonte, Recuerdos de Sócrates, trad. de Juan Zaragoza, Madrid: Gredos, 1993, IV, 4, 10 .

${ }^{62}$ Cfr. P. Hadot, Ejercicios espirituales y filosofía antigua, p. 96.

63 Cfr. P. Hadot, Ejercicios espirituales y filosofía antigua, p. 99.

${ }^{64} \mathrm{P}$. Hadot, La filosofía como forma de vida. Conversaciones con Jeannie Carlier y Arnold I. Davidson, trad. de Mería Cucurella Miquel, Barcelona: Alpha Decay, 2004, p. 170. 
Para Hadot, este proceso de negación y de un naciente interés en sí mismo ha de finalizar en la elevación hacia el pensamiento puro y en una vida conforme a la razón. En Kierkegaard, recordemos que la absoluta negatividad de la ironía socrática significa que toda negación es hecha en virtud de algo superior: la Idea. La cual, sin embargo, Sócrates desconoce. La divinidad que Sócrates albergaba en su interior, al modo de los silenos, solo estaba en Sócrates de forma latente, pero no real. Esto no parece radicalmente distinto de lo propuesto por Hadot, cuando señala que Sócrates en efecto no era un sabio, no poseía el conocimiento de la Idea de Bien ni de Belleza, pero sí era la puerta de acceso a estas.

La reflexión de Hadot en torno a la filosofía antigua y, específicamente, sobre la filosofía de Sócrates, nos muestra un aspecto importante a considerar en el análisis de la ironía socrática como forma de vida, a saber, que si bien Sócrates no es un sabio, pues no alcanza la Idea, su camino negativo plantea la posibilidad de alcanzarla. En lo que sigue defenderé que dicha posibilidad, presente en la ironía socrática, permite que esta pueda ser dominada y, al serlo, constituya el principio de la vida genuinamente humana.

\section{B. La ironía socrática como elemento dominado}

Como lo he mencionado, al hablar de la ironía como elemento dominado, Kierkegaard no hace mención explícita de si esta ironía podría ser la ironía socrática. En su lugar, encontramos algunas afirmaciones que hacen plausible rechazar la ironía romántica como la ironía que podría ser dominada. La principal razón está en que, mientras la ironía dominada le permite al individuo reconciliarse con su realidad, la ironía romántica crea una realidad metafísica, la cual eleva tanto al individuo por encima de su realidad que una reconciliación con esta se hace imposible. La ironía socrática, por su parte, parece plantear esta misma imposibilidad, cuando se muestra que Sócrates nunca alcanzó la Idea, lo positivo, sino que, por el contrario, le bastó la ironía y se entregó por completo a ella. No obstante, esto no implica que la ironía trazada por Sócrates impida el alcance de la Idea, pues, por el contrario, Hegel había mostrado que es gracias a esta que se da paso a una nueva época: la de las escuelas socráticas ${ }^{65}$.

El paso de una época a otra fue para Hegel la justificación histórica de la ironía socrática. Dicho en otras palabras, Hegel sostuvo que la historia

${ }^{65}$ Cfr. G.W.F. Hegel, Lecciones sobre historia de la filosofía II, trad. de Wenceslao Roces, México D.F.: Fondo de Cultura Económica, 1995, p. 8. 
del pensamiento necesitó de la negatividad de Sócrates para que se diera el paso de una época inconsciente a una época en la que la consciencia despertara $^{66}$. La ironía de Sócrates permitió que el individuo rechazara lo que tradicionalmente había asumido como verdadero, siguiéndose de esto un cambio de mirada de lo externo a lo interno, a partir del cual el individuo encontraría, a través de sí mismo, la verdad que lo establecido no le había ofrecido. Esta función que Hegel resaltó de la ironía socrática en la historia del pensamiento no es distinta de la que Kierkegaard señala de la ironía dominada en la vida personal.

Consideremos ahora que, en lo que respecta a la historia del pensamiento, podríamos decir que la ironía socrática tuvo tanto alcance como la vida de Sócrates lo permitió. Es decir: una vez Sócrates murió, la negatividad de su ironía se vio interrumpida y, por ese motivo, fue posible el paso a lo positivo. Si esto se sostiene, habría algo que se pasaría de largo y es que, si la ironía de Sócrates, semejante a la romántica, se hubiera alzado no solo sobre su época, sino sobre toda época pasada y futura, el surgimiento de una nueva época no hubiera sido posible a partir de tal ironía. Pero que Sócrates rechazara su realidad, y solo su realidad, dejó un conjunto de posibilidades por delante, las cuales fueron tomadas y desarrolladas por la posteridad. La ironía socrática, como Kierkegaard la expone, si bien es solo negatividad, es una negatividad que se detiene dando paso a la posibilidad; en este sentido, aunque Sócrates no haya alcanzado la idea, su ironía fue el camino hacia ella.

La historia del pensamiento exigió un Sócrates ironista que permitiera el surgimiento de una nueva época, una época de conciencia. De igual manera, la vida personal necesitaba de una ironía que purificara la existencia de verdades establecidas y le permitiera al individuo encontrar una verdad que guiara la realización de su vida en la realidad. Es plausible decir entonces que, en cuanto que la ironía socrática permitió el paso de una época a otra y brindó al individuo el camino para encontrar la verdad que guiara la existencia propia, ella representa la práctica o ejercicio que Sócrates nos dejó y que constituye o hace posible la vida digna de ser llamada humana.

${ }^{66}$ Cfr. G.W.F. Hegel, Lecciones sobre historia de la filosofía II, p. 73. 


\section{Bibliografía}

Kierkegaard, Søren, Diarios de Kierkegaard, vol. I, trad. de María Binetti, México: UIA, 2011.

—Diarios de Kierkegaard, vol. II, trad. de María Binetti, México: UIA, 2012.

Mi Punto de Vista, trad. de José Miguel Velloso, Madrid: Sarpe, 1985.

Sobre el Concepto de ironía, trad. de Darío Gonzáles, Madrid: Trotta, 2000. Søren Kierkegaards Skrifter. 28 volúmenes de texto y 28 volúmenes de comentario, ed. por Niels Jørgen Cappelørn, Joakim Garff, Jette Knudsen, Johnny Kondrup y Alastair McKinnon, Copenhague: Gad, 1997- 2013.

Aristófanes, Las nubes. Las ranas. Pluto, trad. Francisco Rodríguez y Juan Rodríguez, Madrid: Cátedra, 2006.

Descartes, René, "Discours de la méthode", en Oeuvres et Lettres, París: Gallimard, 1953.

Hadot, Pierre, Ejercicios espirituales y filosofía antigua, trad. Javier Palacio. Madrid: Ediciones Siruela, 2006.

La filosofía como forma de vida. Conversaciones con Jeannie Carlier y Arnold I. Davidson, trad. Mería Cucurella Miquel, Barcelona: Alpha Decay, 2004.

Hegel, G. W. F., Hegel, Lecciones sobre historia de la filosofía II, trad. Wenceslao Roces, México D.F.: Fondo de cultura económica, 1995.

Martensen, Hans Lassen, "Indledningsforedrag til det i November 1834 begyndte logiske Cursus paa den kongelige militaire Høiskole. Af J. L. Heiberg, Lærer i Logik og Æsthetik ved den kgl. Militaire Høiskole”, en Maanedskrift for Litteratur, no. 16, 1836.

Platón, Diálogos Diálogos I, trad. J, calonge Ruiz, E. Lledo Íñigo, C. García Gual, Madrid: Gredos, 1997.

—Diálogos III, trad. M. Martínez Hernández, E. Lledo Íñigo, C. García Gual, Madrid: Gredos, 1997

Otras fuentes consultadas:

Llevadot, Laura, "Negatividad: La figura de Sócrates en la obra de Kierkegaard" en Contrastes, Revista Internacional de Filosofía, vol. XIV, ISSN: 1136-4076, Málaga: Universidad de Málaga, 2009.

Soderquist, Brian, The Isolated Self, Copenhagen: Søren Kierkegaard Research Centre, C.A. Reitzel's Publishers, 2007.

Stewart, Jon, Kierkegaard's Relations to Hegel Reconsidered, Nueva York: Cambridge University Press, 2003.

Torralba, Francesc, Kierkegaard en el laberinto de las máscaras, Salamanca: Colección Persona, 2003. 